\title{
Measurement and Analysis of Logistics Energy Efficiency in China from Perspective of Total Factor Productivity
}

\author{
Zhang Li-Guo ${ }^{*}, 1,2$ \\ ${ }^{1}$ College of Economics and Management, Nanjing University of Aeronautics and Astronautics, China \\ ${ }^{2}$ Department of Science and Technology, Guilin University of Aerospace Technology, China
}

\begin{abstract}
Based on data envelopment analysis model (DEA), this paper constructs a measure function of logistics energy efficiency. Using provincial panel data from 2003 to 2009, it measures logistics energy efficiency in China from perspective of total factor productivity and analyzes the dynamic changes and regional disparity of logistics energy efficiency. The results show that, (1) the average growth rate of energy consume of China logistics is $13.8 \%$, and the output value of that is only $5.7 \%$;(2) The highest efficiency province is Hebei and the lowest is Yunnan which is only 0.3547. (3) The logistics energy efficiency of China in three regions was found while the East is best which 0.815 is, and the West is the worst which is 0.472 .
\end{abstract}

Keywords: Data envelopment analysis model, energy efficiency, logistics industry.

\section{INTRODUCTION}

Logistics industry is one of an important industry of energy consumption in China, especially the consumption of refined oil, ranking first in various industries [1]. And more than $90 \%$ gasoline and $60 \%$ diesel are consumed by it [2]. IPCC 2007 report showed if the energy consumption patterns of logistics industry has no change in future, it would be $80 \%$ higher than current in 2030. Therefore, to study China's logistics energy efficiency measures and identify the factors affect energy efficiency of logistics is necessary.

Rarely current studies focused on the following three perspectives: the first was transport area which was the main area of quantitative research about the logistics energy efficiency. For example, Zhu (2004) [3] studied the energy demand of transport, Zhang (2006) [4] constructed a model of transport energy consumption, Lu (2004) [5] studied the energy consumption of the urban transport optimization problems, Li (2008) [6] studied the urban passenger transport energy consumption, etc. Based on the sustainable development theory, the second perspective studied the logistics energy-saving concept, and through the relevant cases given the appropriate recommendations. For example, $\mathrm{Wu}$ (2011) [7] studied energy saving of supply management from profit and environment goals, Ubeda (2011) [8] studied a case of logistics energy saving in Eroski, etc. The last perspective focused on multi-objective model of the logistics supply chain and energy efficiency. For example, Frota (2008) [9] designed energy-efficient logistics network using the weighting method, He (2012) [10] using multi-objective evolutionary algorithm to obtain the logistics enterprise

*Address correspondence to this author at the Department of Science and Technology, Guilin University of Aerospace Technology, Jinji Road No. 2, Guilin, Postcard: 541004, China; Tel: 0086-773-2295513;

E-mail: zhangliguotony@163.com energy Pareto front, and carried out analysis of efficiency border, Zajac (2011) [11] established a logistics warehouse evaluation model of energy consumption, Yang (2012) [12] constructed a container terminal logistics system evaluation model of energy consumption.

Logistics industry contains many various areas, in which existing trade-off effect, so the energy consumption of one area best does not mean the entire industry is best. Qualitative case studies can't expose global issues and theoretical models need to be tested in practical applications. Therefore, from perspective of the logistics industry as a whole explore and empirical methods for energy efficiency industry practical significance will be a better perspective. From perspective of the entire logistics, empirical research methods, analysis of China's logistics, this paper discussed the current state of energy efficiency, and analyzed the influencing factors for the logistics, so that it can provide another reference energy saving idea.

\section{MATERIALS AND METHODOLOGY}

\subsection{Construction of Logistics Energy Efficiency Function}

The most used model to measure energy efficiency is CCR-DEA of constant return to scale. To measure logistics energy efficiency, this paper takes input oriented CCR-DEA model which means the output under is certain and the input minimization is need. In this paper the energy efficiency measure function of logistics industry by using CCR-DEA model input oriented is constructed as follows:

We assume that there are $\mathrm{n}$ logistics decision-making units (LDMUs), each $L M D U_{\mathrm{j}}(j=1,2 \cdots, n)$ of which transforms a m-dimensional row vector of inputs $X_{j} \in R_{+}^{m}$ into a s-dimensional row vector of outputs $X_{j} \in R_{+}^{s}$. The 
standard CCR-DEA model can be explained as the following program.

$\max h_{0}=\frac{\sum_{r=1}^{s} u_{r} y_{r j_{0}}}{\sum_{i=1}^{m} v_{i} x_{i j_{0}}}$

s.t. $\frac{\sum_{r=1}^{s} u_{r} y_{r j}}{\sum_{i=1}^{m} v_{i} x_{i j}} \leq 1, j=1,2, \cdots n$

$u_{r} \geq 0, v_{i} \geq 0, r=1,2 \cdots s, i=1,2 \cdots m$

Based on Charnes-Cooper transformation technique, we can get the input oriented CCR-DEA model as followed:

$$
\begin{aligned}
& \min \left[\theta-\varepsilon\left(\hat{e}^{T} s_{i}^{-}+e^{T} s_{i}^{+}\right)\right] \\
& \text {s.t. }\left\{\begin{array}{l}
\sum_{j=1}^{n} \lambda_{j} x_{i j}+s_{i}^{-}=\theta x_{i j_{0}} \\
\sum_{j=1}^{n} \lambda_{j} y_{r j}-s_{r}^{+}=y_{r j_{0}} \\
\lambda_{j} \geq 0, s_{i}^{-} \geq 0, s_{r}^{+} \geq 0 \\
j=1,2, \cdots n . i=1,2, \cdots m . r=1,2, \cdots s
\end{array}\right.
\end{aligned}
$$

According to equation (2), we can get following conclusions: (1) If $\theta^{*}=1, s^{-}$and $s^{+}$are 0 , we called the corresponding independent logistics decision-making unit DEA efficient. If $\theta^{*}=1, s^{-} \neq 0$ or $s^{+} \neq 0$, we called units weak DEA efficient; (3) If $\theta^{*}<1$, we called units weak nonDEA efficient. For the case of (1), various input factors had been effectively utilized, the energy efficiency is the best. For (2) and (3), logistics decision-making unit of inputs underutilized, there are input redundancies. Based type (2), we got the redundant input quantity $\Delta x_{i j_{0}}=\left(1-\theta^{*}\right) x_{i j_{0}}+s^{-}$. According to $\mathrm{Hu}$ (2006) total factor concept definition of energy efficiency, the energy efficiency measures can be showed as follows:

$$
\begin{aligned}
L E E_{D M U_{j_{0}}}= & \frac{D M U_{j_{0}} \text { energy goals inputs }}{D M U_{j_{0}} \text { energy actual inputs }} \\
= & \frac{x_{i j_{0}}-\Delta x_{i j_{0}}}{x_{i j_{0}}}
\end{aligned}
$$

\subsection{Variables and data}

\subsubsection{Variables}

The input variables of logistics efficiency measure in current studies input are the follows: He (2006) [13] chooses GDP, consumer capacity, fixed asset investment, road network density, logistics companies' personnel profitability and land investment, labor indicators as input variables; Yu (2010) [14] and Ou (2010) [15] selected logistics investment in fixed assets and current employees; Zhong (2010) [16] and Tian (2009) [17] selected net fixed assets and current employees; Wang(2012) [18] selected fixed asset investment, current employees and energy consumption. Based on these studies, this paper selected fixed assets investment of logistics, current employees, and energy consumption as input variables.

Output variables were mainly logistics output, GDP, cargo turnover, passenger turnover. Based on the correlation between the volume of passenger freight and logistics output, avoiding double counted, combined with the energy efficiency studies, this paper selected logistics output as output variables.

\subsubsection{Data Sources and Selection}

Any current statistical classification has logistics industry; even the most advanced statistical system which names North American Industry Classification System (NAICS) does not set up logistics as a statistical category. From China tertiary industry Statistical Yearbook, which has been published since 2006, transportation, storage and postal services accounted for more than $83 \%$ of logistics. So it can largely reflect logistics industry. For data availability, many current studies used transportation, storage and postal industry to represent logistics industry, so this article can serve as a source of data. Because transport, storage and postal statistics in various current statistical yearbooks were started from 2003, based on data availability and consistency, this paper selected years from 2003 to 2009.

(1) Current employees: Select current employees of transportation, storage and postal industry each year from 2003 to 2009 of all regions in China Statistical Yearbook

(2) Fixed asset investment was based on transportation, storage and postal fixed investment of all regions in China Statistical Yearbook. First, we used GDP deflator to transform each year of 2003-2009 fixed assets investments into 1978 price which can eliminate the interference of price factors. Then, considering capital stock and the study of Xu (2010) [19], our capital stock is estimated to 5.18445 trillion Yuan (1978 prices) in 2000. Combined with investment in fixed assets, we get the scale of investment in capital stock. According to this scale, we get the 2000 provincial capital stock by which is multiplied by the provincial transportation, storage and postal investment in fixed assets. For the selection of depreciation rate, we used $12.1 \%$ (Liu, 2007) [20]. Finally, according to the perpetual inventory method we can get various regions of the logistics capital stock.

Energy inputs data of logistics were come from China Energy Statistical. For the missing data in these yearbooks, we referred to the corresponding provinces Statistical Yearbook. As lack of Tibet's energy data, we selected other 30 regions. Using energy conversion factors, we get the standard coal consumption for power generation coal of each regional transportation, storage and postal industry.

Logistics output: We selected the output of all regions in China Statistical Yearbook in 2003-2009 of 
Table 1. Provincial logistics energy efficiency from 2003 to 2009 in China.

\begin{tabular}{|c|c|c|c|c|c|c|c|c|}
\hline & 2003 & 2004 & 2005 & 2006 & 2007 & 2008 & 2009 & Means \\
\hline Beijing & 1 & 1 & 1 & 1 & 0.823 & 0.544 & 0.621 & 0.855 \\
\hline Tianjin & 0.817 & 0.915 & 0.828 & 0.724 & 0.668 & 0.6 & 0.758 & 0.759 \\
\hline Hebei & 1 & 1 & 0.989 & 1 & 1 & 1 & 1 & 0.998 \\
\hline Shanxi & 0.497 & 0.873 & 0.899 & 0.788 & 0.799 & 0.652 & 0.648 & 0.737 \\
\hline Inner Mongolia & 0.456 & 0.763 & 0.696 & 0.684 & 0.676 & 0.663 & 0.813 & 0.679 \\
\hline Liaoning & 0.82 & 0.765 & 0.783 & 0.691 & 0.645 & 0.519 & 0.606 & 0.690 \\
\hline Jilin & 0.474 & 0.73 & 0.651 & 0.594 & 0.589 & 0.512 & 0.559 & 0.587 \\
\hline Heilongjiang & 0.512 & 0.705 & 0.701 & 0.562 & 0.557 & 0.522 & 0.493 & 0.579 \\
\hline Shanghai & 0.81 & 0.998 & 0.937 & 0.81 & 0.656 & 0.499 & 0.44 & 0.736 \\
\hline Jiangsu & 0.683 & 0.669 & 0.733 & 0.78 & 0.727 & 0.736 & 0.792 & 0.731 \\
\hline Zhejiang & 0.959 & 0.835 & 0.841 & 0.849 & 0.815 & 0.693 & 0.634 & 0.804 \\
\hline Anhui & 0.549 & 0.848 & 1 & 0.905 & 0.772 & 0.758 & 0.559 & 0.770 \\
\hline Fujian & 1 & 1 & 1 & 0.993 & 1 & 0.881 & 0.792 & 0.952 \\
\hline Jiangxi & 0.678 & 0.753 & 0.807 & 0.656 & 0.624 & 0.639 & 0.541 & 0.671 \\
\hline Shandong & 0.71 & 0.996 & 1 & 1 & 1 & 1 & 1 & 0.958 \\
\hline Henan & 0.863 & 0.734 & 0.903 & 0.903 & 0.803 & 0.836 & 0.56 & 0.800 \\
\hline Hubei & 0.443 & 0.554 & 0.527 & 0.486 & 0.473 & 0.458 & 0.509 & 0.493 \\
\hline Hunan & 0.523 & 0.642 & 0.659 & 0.607 & 0.598 & 0.553 & 0.611 & 0.599 \\
\hline Guangdong & 0.794 & 0.733 & 0.715 & 0.629 & 0.622 & 0.561 & 0.627 & 0.669 \\
\hline Guangxi & 0.531 & 0.569 & 0.542 & 0.497 & 0.507 & 0.477 & 0.451 & 0.511 \\
\hline Hainan & 0.429 & 0.49 & 0.47 & 0.465 & 0.45 & 0.404 & 0.358 & 0.438 \\
\hline Chongqing & 0.524 & 0.715 & 0.712 & 0.637 & 0.518 & 0.474 & 0.452 & 0.576 \\
\hline Sichuan & 0.449 & 0.561 & 0.57 & 0.525 & 0.484 & 0.466 & 0.374 & 0.490 \\
\hline Guizhou & 0.291 & 0.429 & 0.44 & 0.428 & 0.42 & 0.369 & 0.747 & 0.446 \\
\hline Yunnan & 0.31 & 0.563 & 0.407 & 0.352 & 0.34 & 0.296 & 0.215 & 0.355 \\
\hline Shaanxi & 0.405 & 0.474 & 0.503 & 0.448 & 0.412 & 0.396 & 0.433 & 0.439 \\
\hline Gansu & 0.19 & 0.44 & 0.502 & 0.463 & 0.451 & 0.499 & 0.502 & 0.435 \\
\hline Qinghai & 0.47 & 0.642 & 0.683 & 0.631 & 0.366 & 0.263 & 0.257 & 0.473 \\
\hline Ningxia & 0.226 & 0.591 & 0.46 & 0.433 & 0.413 & 0.384 & 0.653 & 0.451 \\
\hline Xinjiang & 0.292 & 0.491 & 0.421 & 0.397 & 0.365 & 0.327 & 0.337 & 0.376 \\
\hline
\end{tabular}

transportation, storage and postal industry and converted them into 1978 price.
As we can see from Fig. (1) that the consumption of standard coal consumption for power generation coal of logistics industry in China has been an increasing trend

Table 2. Regional logistics energy efficiency from 2003 to 2009 in China.

\begin{tabular}{|c|c|c|c|c|c|c|c|c|}
\hline & 2003 & 2004 & 2005 & 2006 & 2007 & 2008 & 2009 & Means \\
\hline East China & 0.860 & 0.892 & 0.883 & 0.848 & 0.796 & 0.703 & 0.727 & 0.815 \\
\hline Middle China & 0.567 & 0.730 & 0.768 & 0.688 & 0.652 & 0.616 & 0.56 & 0.654 \\
\hline West China & 0.381 & 0.561 & 0.534 & 0.497 & 0.450 & 0.418 & 0.466 & 0.472 \\
\hline Nation & 0.590 & 0.716 & 0.713 & 0.665 & 0.619 & 0.566 & 0.578 & 0.635 \\
\hline
\end{tabular}




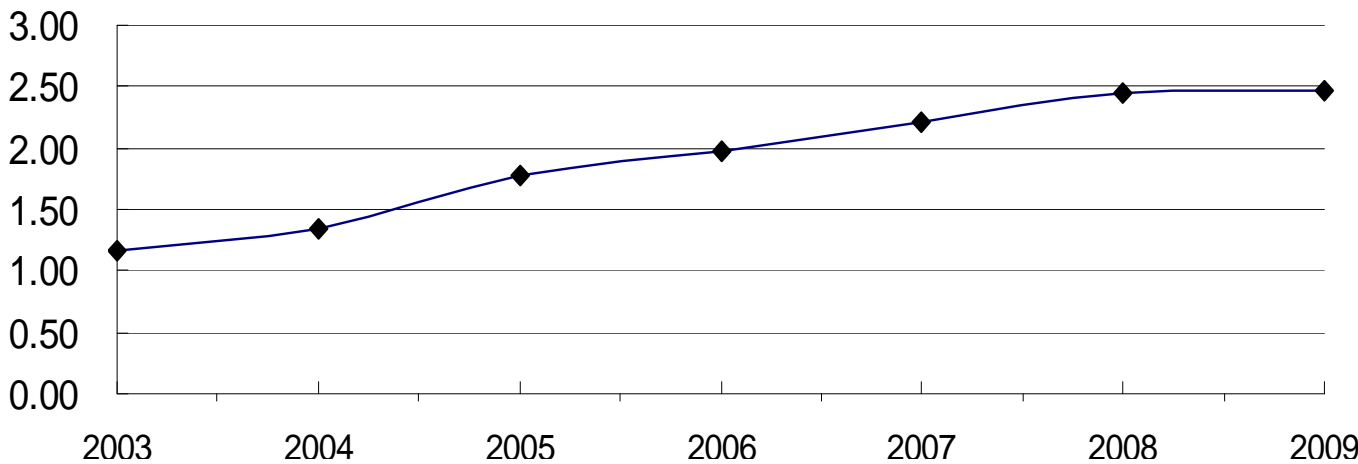

Fig. (1). The energy consumption trend of logistics industry from 2003 to 2009 in China.

which increased form 1.16 billon tons in 2003 to 2.47 billion tons in 2009.

\section{LOGISTICS TOTAL FACTOR ENERGY EFFICIENCY MEASUREMENT AND ANALYSIS}

\subsection{Energy Efficiency Results}

Using equation (1) and (2), we can calculate the logistics energy efficiency of 30 areas, three regional and national values from 2003 to 2009. From Tables $\mathbf{1}$ and 2, we get the following conclusions:

Provincial energy efficiency of the logistics. Table $\mathbf{1}$ shows the China's logistics energy efficiency of various regions from 2003 to 2009. From Table 1, we find Hebei, Fujian and Shandong are highest energy efficiency that means were above 0.9 . These three areas' rates are closed to logistics energy efficiency frontiers in 2003-2009. Beijing, Zhejiang and Henan are in the second echelon that energy efficiency means were more than 0.8 . The lowest energy efficiency areas are Gansu and Xinjiang bellowed 0.4. The highest efficiency province is Hebei and the lowest is Yunnan which only reached 0.3547 .

(2) Regional logistics energy efficiency. From region of eastern, middle and western perspective, the logistics energy efficiency is shown in Table 2. The energy efficiency of China's logistics showed decreased from east to west between 2003 and 2009. Eastern average energy efficiency was highest which reached 0.815 , middle second, up to 0.654 , and minimum of 0.472 western.

(3) National logistics energy efficiency. From the perspective of country, the logistics energy efficiency has experienced in 2004 before rising process, and then had been showing a downward trend until 2008; in 2009 the rising trend has emerged. This feature is called the cyclical volatility and class periods by Meng (2012) [21].

\subsection{Analysis of Energy Efficiency Results}

Overall, the energy efficiency trend of China's logistics had been increased first and decreased then upward. For Table 1 and Table 2, the empirical results can be analyzed from the following three aspects:

(1) There was a positive correlation between economic development and energy efficiency. From Table 2, we see that energy efficiency of China's logistics followed a downward trend from the eastern to the western which may be due to the economic development. The logistics economies of scale can be better reflected in developed regions where the amount of energy consumption was much lower. At developed regions, the goods could be easier collected and the utilization of conveyance and logistics facilities could be higher. Therefore, energy consumption per unit of output was greater and the energy efficiency was higher.

(2) There is a positive correlation between city logistics development and energy efficiency. From 2004 to 2008, China economy had been a rapid growth, but the logistics energy efficiency preached a downward trend. The reason may be due to city logistics had been a low development during this period. With the economic development, cities expanded rapidly and the amount of city logistics increased fast. As the rapid development of city cars since 2004, severe traffic congestion problems emerged. Continued frequent urban traffic congestion brought a great impact to the city logistics development, which not only led to "the last mile" problems, but also made the urban logistics energy efficiency much lower. Therefore it is an important reason of the dropping of logistics energy efficiency in various regions that urban logistics was inefficiency since 2004.

(3) There is a positive correlation between economic stimulus policies and logistics energy efficiency. There was an upward trend of logistics energy efficiency in various regions in 2009 which may be related with the Chinese government's stimulus policies. Facing the worst recession, Chinese government put forward a package of economic stimulus plans and began a large-scale investment. The main areas of the investment were the construction of logistics infrastructure which improved the logistics of energy utilization.

\section{CONCLUSION}

According to 30 areas' logistics energy consumption panel data in 2003-2009, the descriptive statistics, total amount of energy consumed changes and regional differences, the relation between energy consumption and output value was studied in this paper. Using the CCR-DEA model, the logistics energy efficiency changes of 30 areas 
and municipalities in seven years were got and the logistics energy efficiency from eastern, middle and western in a regional perspective was found.

First: the logistics of China's total energy consumption showed a significant increasing trend in the sample years which may be related to the rapid development of China's economy;

Second: the average growth rate of logistics energy consumption is much higher than that of the output, which may be related with China's logistics, extensive development patterns. In 2009 the State Council draw "logistics restructuring and revitalization plans" may be for this reason;

Third, the logistics energy efficiency had generally increased and then decreased. City logistics development lag may be an important cause leading to the decrease of logistics energy efficiency;

Fourth: From the analysis of the regional perspective, the performance of energy efficiency was eastern better than the middle and middle better than west. The reason may be due to the economically developed eastern, the logistics facilities and equipment rate was higher than the middle and western; the logistics economic scale can effectively be reflected.

\section{CONFLICT OF INTEREST}

The author confirms that there are no known conflict of interest associated with this publication.

\section{ACKNOWLEDGEMENTS}

This work is supported by scientific research of GuangXi Education Department under Grant No. 201012MS218 and No. SK13YB119. It is also supported by the Humanities and Social Science Foundation of Guangxi Aviation Logistics Research Center. I'd like to thank anonymous referees for their helpful comments.

\section{REFERENCES}

[1] F. Wang, and G.F. Feng, "Elasticities of China's carbon intensity with respect to industrial development energy efficiency and intermediate input coefficients", The Journal of Quantitative and Technical Economics, no. 5, pp. 50-62, 2012.

[2] Y. Tao, and H.F. Xue, "Study on decision-making system model of transportation energy consuming", Computer Engineering and Applications, vol.45, no.5, pp.5-9, 2009.

[3] S. L. Zhu, "Method of traffic demand forecast and transportation energy demand", The Journal of Quantitative and Technical Economics, no.5, pp. 100-108, 2004.
[4] S. W. Zhang, and K.J. Jiang, “ Energy consumption of China's transport development and its policy implications", China Soft Science, no.5, pp.58-62, 2006.

[5] H. P. Lu, and J.W. Wang, "Urban transport structure optimization based on energy consumption ", Journal of Tsinghua University (Science and Technology), vol. 44, no. 3, pp. 382-386, 2004.

[6] Z. Li, F. Fu, and T. Gao, "Decomposition analysis of motorized passenger transport energy demand changes in selected Chinese cities", Journal of Tsinghua University (Science and Technology), vol.48, pp. 1945-1948, 2008.

[7] Z. H. Wu, and M. Pagell, "Balancing priorities: decision-making in sustainable supply chain management", Journal of Operations Management, vol. 29, no. 6, pp. 577-590, 2011.

[8] S. Ubeda, "Green logistics at Eroski : a case study", International Journal of Production Economics, vol. 131, no. 1, pp. 44-51, 2011.

[9] N. J. Frota, "Designing and evaluating sustainable logistics networks", International Journal of Production Economics, vol. 111, no. 2, pp.195-208, 2008.

[10] B. He, "Models and efficiency boundary analysis of green logistics networks", Chinese Journal of Management Science, vol.20, no.3, pp.138-144. 2012

[11] P. Zajac, "The idea of the model of evaluation of logistics warehouse systems with taking their energy consumption under consideration", Archives of Civil and Mechanical Engineering, vol.11, no.2, pp. 479-492, 2011

[12] B. Yang, and Y.Y. Guo, "Research on the energy consumption evaluation model of container terminal logistics system", Applied Mechanics and Materials, vol.157, pp.1224-1229, 2012.

[13] Z. Q. He, and L.Y. Sun, "Evaluation on the relative efficiency of regional logistics in China", Science Research Mangement, vol.27, no.6, pp.144-149, 2006.

[14] Z. Y. Yu, "An empirical study on the efficiency of China's logistics industry and its factors". Industrial Economics Reaearch, no.1, pp.65-71, 2010.

[15] X.X. Ou-Yang, "Empirical analyses on China's regional logistics matching efficiency and its influencing factors", Finance and Trade Research, no.6, pp.23-30, 2010.

[16] Z. CH. Zhong, "Research on the efficiency of logistics industry China based on three-stage DEA model". Journal of Finance and Economics, vol.36, no.9, pp.80-90, 2010.

[17] G. Tian, and N.Li, "Research on technical progress and technical efficiency of China's logistics industry", The Journal of Quantitative \& Technical Economics, no.2, pp.76-87, 2009.

[18] G. W. Wang, and Y. Y. Ma, "The efficiency of regional logistics industry in China", Systems Engineering, vol.30, no.3, pp.66-75, 2012.

[19] J. Xu, "Revaluation of capital stock in China", Statistical Research, vol.27, no.12, pp.72-77, 2010

[20] B. L. Liu, and Y. Liu, "Estimation of our country highway and waterway transportation provincial capital stock (1952-2004)", Journal of Beijing Jiaotong University (Social Sciences Edit ion), vol. 6, no. 3, pp. 44-48, 2007.

[21] C.Meng, and Y.J.Chen, "China's inter-regional energy efficiency during the period of 1995-2010: Descriptive statistic and DEA analysis based on provincial panel data", Finance and Trade Economics, no.6, pp. 116-123, 2012

(C) Zhang Li-Guo; Licensee Bentham Open.

This is an open access article licensed under the terms of the Creative Commons Attribution Non-Commercial License (http://creativecommons.org/licenses/by-nc/3.0/) which permits unrestricted, non-commercial use, distribution and reproduction in any medium, provided the work is properly cited. 